\title{
O PROJETO POLÍTICO-PEDAGÓGICO - CONSIDERAÇÕES ACERCA DA GESTÃO PARA A AUTONOMIA DA ESCOLA
}

\author{
THE POLITICAL-PEDAGOGICAL PROJECT - CONSIDERATIONS REGARDING THE MANAGEMENT FOR SCHOOL AUTONOMY
}

EL PROYECTO POLÍTICO-PEDAGÓGICO - CONSIDERACIONES ACERCA DE LA GESTIÓN PARA LA AUTONOMÍA DE LA ESCUELA

COSTA, Daianny Madalena 1

\begin{abstract}
RESUMO
O projeto político-pedagógico (PPP) nos é objeto neste artigo, no sentido de procurar sua contribuição à gestão educacional. A investigação realizada baliza-se sobre os pressupostos da pesquisa participativa e da abordagem qualitativa, por meio da análise dos documentos e de entrevistas com as equipes gestoras de três escolas municipais em que discute alguns meandros entre as mesmas e uma Secretaria Municipal de Educação (SMED). A partir disso, concluímos que o PPP potencializa a ideia de uma gestão participativa, quando realizado coletivamente e construído entre os membros das escolas e da SMED.
\end{abstract}

Palavras-chave: PPP. Gestão Educacional. Autonomia. Secretaria Municipal de Educação. Escola.

\section{ABSTRACT}

The political-pedagogical project (PPP) is the object of this research, in the sense of seeking its contribution to educational management. The research is based on the assumptions of the participatory research and the qualitative approach, through the analysis of the documents and interviews with the management teams of three municipal schools in which some discussions are held between the head office of the Municipal Department of Education (SMED) and the schools. From this, we conclude that the PPP enhances the idea of a participatory management, when is done collectively and built between the members of the schools and the SMED.

Keywords: PPP. Educational management. Autonomy. Municipal Secretary of Education. School.

\section{RESUMEN}

El proyecto político-pedagógico (PPP) es nuestro objeto en este artículo, en el sentido de buscar su contribución a la gestión educacional. La investigación realizada es calculada sobre los presupuestos de la investigación participativa y del abordaje cualitativo, por medio del análisis de los documentos y de las entrevistas con los equipos gestores de tres escuelas municipales en las que se tienen discusiones entre ellas y una Secretaría Municipal de Educación (SMED). A partir de eso, concluimos que el PPP potencializa la idea de una gestión participativa, cuando es realizada colectivamente y es construída entre los miembros de las escuelas y de la SMED.

Palabras clave: PPP. Gestión Educacional. Autonomía. Secretaría Municipal de Educación. Escuela.

\footnotetext{
${ }^{1}$ Universidade do Vale do Rio dos Sinos - UNISINOS - Porto Alegre - Rio Grande do Sul - Brasil.
} 


\section{INTRODUÇÃO}

O fato de empregarmos nossos esforços em favor de uma reflexão provocativa e dialógica acerca do Projeto Político-Pedagógico (PPP), instituído pela Lei de Diretrizes e Bases da Educação Nacional (LDBEN), (BRASIL,1996), significa dizer que, mesmo estando prescrito sob o ordenamento legal e, possivelmente caracterizado como elemento produzido por meio de muitos atores do contexto educacional, não significa que sua implementação dar-se-á naturalmente (COSTA, 2017).

Diante disso, pensar sobre as possibilidades da escola se fazer como instituição autônoma, a partir de uma prática reflexiva, que se pense, e que, para isso introduza um método participativo em seu planejamento, ainda está na pauta da construção educacional brasileira, para além da existência da lei. Mais ainda, que isso se faça numa perspectiva de política educacional, em parceria com sua mantenedora.

Esse artigo, portanto, vem contribuir com tal ideia. Da possibilidade de problematizar acerca do projeto de escola - ato político-(e)-pedagógico - compreendendo para isso, que todo o processo educacional, administrativo-pedagógico, tão necessário para a organização escolar, para sua função social, requer compromisso entre todos os sujeitos do estabelecimento educativo (PARO, 2015; GANDIN; GANDIN, 2011; VEIGA, 2013) e comprometimento também, dos profissionais que desenvolvem o acompanhamento, a supervisão, aqueles que são responsáveis pela produção das políticas educacionais no âmbito municipal - que participam da sede da Secretaria Municipal de Educação.

Por isso, para a construção do PPP é necessário refletir sobre o que almejam construir? Para quê? Com quem? E, posteriormente, propor uma gestão educacional que igualmente dialogue com a organização realizada e como se ocupará para contribuir na viabilização do que compreendem necessário.

\section{O PERCURSO METODOLÓGICO}

Sendo assim, o objetivo dessa pesquisa, que realizamos junto a uma rede municipal de educação na região metropolitana de Porto Alegre/RS intitula-se, "Articulações entre a gestão educacional, o projeto político-pedagógico e o currículo escolar - reflexões necessárias". A partir dela trazemos um recorte acerca da relação existente no campo da gestão educacional e da autonomia da escola, pois os projetos político-pedagógicos existentes nas unidades escolares analisadas foram materializados por meio da solicitação institucional da sede da Secretaria Municipal de Educação a todos os estabelecimentos escolares, no ano de 2012.

Por acreditarmos que há uma estreita relação entre ambas - sede da secretaria municipal de educação e as escolas (que estão sob sua manutenção), a qual se expressa na interlocução entre as políticas educacionais e o fazer cotidiano em cada unidade escolar, produzimos este artigo que objetiva precipuamente discutir sobre a construção e efetivação desses documentos sob a perspectiva de contribuição para a gestão da educação. Disso decorreu uma análise de três PPPs e um conjunto de 
entrevistas realizadas junto aos membros das equipes gestoras desses estabelecimentos educacionais, que, por assim dizer, são os sujeitos que refletem e analisam acerca do objeto de estudo desse trabalho - (o PPP), para que assim, possamos penetrar no real (GHEDIN; FRANCO, 2008). Consequentemente há um conjunto de considerações e engendramentos com a nossa proposta teórico-metodológica e com o desenho da pesquisa, que levaram a promover aproximações, distanciamentos e contradições.

Desse modo, a investigação perspectiva-se sobre a abordagem qualitativa e como propõe Minayo (2016) empenha-se na produção de um conhecimento que favoreça à descoberta de possíveis compreensões, contradições, disputas existentes nos processos educacionais. Dito isso, a metodologia que nos orienta está articulada ao seu referencial teórico, que tem um profundo compromisso em valorizar a docência como atividade intelectual, inserida em condições históricas, sociopolíticas e culturais que produzem tensões, mas, do ponto de vista de sua (re)construção, não determinações que a impossibilitem. É um referencial metodológico que utiliza os princípios da reflexão hermenêutica e do paradigma epistemológico dialético, para a construção de uma análise que parta da realidade e consequentemente invista em (re)invenções (GHEDIN; FRANCO, 2008).

A investigação iniciou em 2016 e tem como cenário empírico três escolas indicadas pela coordenação da sede da Secretaria Municipal de Educação (SMED). No ano de 2017, as três instituições atenderam cerca de quatro mil estudantes, entre os últimos anos da Educação Infantil e o Ensino Fundamental completo, constituída pela modalidade de anos/seriados e, por meio das etapas da Educação de Jovens e Adultos a todos aqueles que não tiveram acesso na idade própria.

Ao todo, o município é responsável por 28 escolas - da educação infantil aos anos finais do ensino fundamental, totalizando quase dezesseis mil alunos. Com um quadro de cento e treze especialistas (supervisores escolares e orientadores educacionais) e novecentos e setenta e dois professores. Os vinte e oito diretores e seus vices diretores (esses últimos encontrados somente nas escolas com mais alunos), são professores efetivos do quadro do magistério municipal e indicados pelo secretário municipal de educação da cidade.

Na sede da Secretaria Municipal de Educação encontramos no setor pedagógico, o qual realiza o acompanhamento às escolas, professores da rede municipal que são convidados a participarem da condução dos trabalhos educacionais na cidade, tornam-se "referências" em temáticas como educação infantil, ensino fundamental, educação de jovens e adultos, educação especial, erradicação do trabalho infantil, entre tantas outras. Esses assessores, como são denominados, em duplas, acompanham todas as escolas municipais. Cada par de profissionais corresponde a quatro escolas mantidas pelo poder municipal.

Diante desse cenário, propomos uma pesquisa participativa, comprometida sociopoliticamente com o contexto educacional em que estão inseridas. Uma metodologia que possa buscar novos caminhos, por meio de uma reflexão coletiva acerca da escola e seus fazeres, no sentido de transformar as práticas existentes e melhorar as condições vividas (STRECK; ADAMS, 2014) na direção de uma educação que dialoga com os aspectos expressos em seus PPPs.

Os instrumentos para a coleta de dados, portanto, são os projetos das respectivas escolas e as entrevistas coletivas e semiestruturadas, empreendidas com as referentes equipes gestoras de cada 
um dos estabelecimentos escolares, as quais totalizaram quatro momentos distintos, com mais de sete horas de gravação e trinta e nove páginas conforme degravação. Cada equipe foi entrevistada separadamente uma da outra, em seu local de trabalho. Numa única entidade escolar houve duas entrevistas, pois nem todos os membros da equipe encontravam-se trabalhando naquele mesmo momento. Esses diálogos contaram ao todo, com vinte pessoas: três diretores; três vices diretores, e quatorze pedagogos concursados, que se dividem nos setores de orientação pedagógica e supervisão escolar.

Sobre a análise dos dados investiremos em estranhamentos, distanciamentos e aproximações. Por isso, a análise de conteúdo, que vislumbra a triangulação de diversos elementos é-nos a escolha feita para esse momento.

\footnotetext{
Coerentes com nossos posicionamentos anteriores, afirmamos que toda leitura e toda análise textual já é uma interpretação. Entretanto, pretendemos agora ampliar um pouco mais a discussão sobre interpretação. No contexto da análise textual, da forma como a compreendemos, interpretar é construir novos sentidos e compreensões afastando-se do imediato e exercitando uma abstração em relação às formas mais imediatas de leitura de significados de um conjunto de textos. Interpretar é um exercício de construir e de expressar uma compreensão mais aprofundada, indo além da expressão de construções obtidas dos textos e de um exercício meramente descritivo. É nossa convicção de que uma pesquisa de qualidade necessita atingir essa profundidade maior de interpretação, não ficando numa descrição excessivamente superficial dos resultados da análise (MORAES, 2003, p. 204).
}

Sendo assim, a pesquisa como uma prática partilhada (STRECK; ADAMS; 2014), que requer interpretações para ir além do exercício de descrever o "objeto" (MORAES, 2003) e nosso propósito de refletir acerca do PPP e sua relação com a gestão escolar, tem por desafio construir efetivamente uma possibilidade de constante repensar no cotidiano da rede escolar, que encare os desafios e construa caminhos possíveis para a educação proposta em seus documentos.

\section{O PROJETO POLÍTICO-PEDAGÓGICO - INTERPELAÇÕES A PARTIR DOS ATORES DA ESCOLA}

$\mathrm{Na}$ busca de compreender a contribuição do projeto político-pedagógico para a unidade escolar e sua gestão, indagamos sua finalidade a partir das seguintes problematizações: constitui-se num documento que se funda na participação dos atores envolvidos no cotidiano escolar e propõe uma constante reflexão acerca da escola, para que possa efetivar um trabalho organizacional daquilo que a instituição deseja ser. Ou ao contrário disso, caracteriza-se como algo enfadonho, burocrático, que ocupa o tempo dos profissionais da educação em materializá-lo do ponto de vista da confecção do documento, mas não dialoga com os desejos da unidade educativa, no sentido de seu devir, nem serve para ajudar os gestores em seu dia a dia.

Obviamente, à guisa de problematização trazemos as pontuações anteriores, porém, defendemos que o PPP é uma forma da escola se pôr a avaliar sobre a realidade que tem, declarando suas necessidades, suas concepções, seus rumos e seus percursos para viabilizá-lo. Sendo, nesse sentido uma parte da organização escolar e seu planejamento. Para isso, sua construção requer responder, mesmo que provisoriamente, as ideias que os sujeitos da vida escolar têm sobre o tempo em que vivem, sobre a sociedade onde se encontram. O que querem ajudar a formar e, para realizá-lo, 
quais intenções manifestam, como pretendem alcançá-las e o que farão para isso. Supomos, obviamente, que poderá haver um conjunto de dificuldades entre os pressupostos que têm, e como poderão executá-los, principalmente no que se refere à sua relação com o sistema organizacional no qual estão inseridos, contudo, cremos que por meio do PPP e do que ele traz como proposição, os atores da escola se põem a interpelar sobre sua própria atividade e finalidade, buscando concretizar seus objetivos.

Para isso, portanto, julgamos ser necessário, num primeiro momento, exprimirmos, mesmo que rapidamente, sobre a finalidade do estabelecimento escolar, afinal, abarca modos muito distintos de ser pensada, com diferentes pontos de vista de sua inserção social, cultural, ética (ESTÊVÃO, 2002). Dessa maneira, compreendida como unidade básica do sistema educacional relacionada à formação humana, onde tudo é pedagógico e todos educam (LIBÂNEO; OLIVEIRA; TOSCHI, 2012) comungamos com a definição trazida por Roldão (2003), de que a escola é uma instituição social, porque atende a "apelos" da sociedade, está organizada para responder a um tempo determinado e por isso, tem um currículo específico. Para que essa ideia seja compreendida, é preciso relacionar o conceito sugerido por Russo (2004), de que é o lugar de formação dos sujeitos da educação, por meio de uma prática reflexiva e criadora para sua emancipação.

A escola constitui-se, portanto, por um grupo social que extrapola as múltiplas e mútuas normatizações que lhe são determinadas (PARO, 2011) e para o pesquisador serve compreender que

da realidade escolar, o importante é considerar que, muito embora essas práticas nem sempre sejam passíveis de antecipação no plano ideal, o fato de elas existirem torna possível examinálas e procurar descobrir seu vínculo com as ordenações racionais, de modo a identificar, mais ou menos precisamente, que medidas as ocasionaram e quais são as possibilidades de iniciativas que produzam sua mudança ou sua afirmação (PARO, 2011, p. 20).

A esses entendimentos, por fim, juntamos o sugerido por Veiga (2013, p. 11) de que a escola "é o lugar de concepção, realização e avalição do projeto educativo". Nessa complexidade de considerações, temos o que sustenta nossa orientação - de que o PPP é um documento imprescindível para a escola, porque guarda as possibilidades de fazer-se numa perspectiva de incremento de sua autonomia e seu empoderamento para a construção de sua identidade e seu devir. Por isso, Paro (2011) e Veiga (2013) ajudam-nos a compreender que é necessário para a gestão escolar, a prática de interrogar acerca dos impeditivos que aparecem como obstáculos para a existência de seus propósitos.

Assim sendo, por ser projeto, propõe a direção de seu compromisso, e nesse mesmo modo, revela sua intenção política e pedagógica. Por isso, podemos dizer que

político e pedagógico têm assim uma significação indissociável. Neste sentido é que se deve considerar o projeto político-pedagógico como um processo permanente de reflexão e discussão dos problemas da escola, na busca de alternativas viáveis à efetivação de sua intencionalidade. (VEIGA, 2013, p. 13).

Isso posto, nosso entendimento, então é de que o PPP da instituição escolar é a sua expressão documentada, ou seja, uma possibilidade de síntese de suas discussões, de seus entendimentos, de seus anseios, intenções e propósitos. Daquilo que deseja construir com/na sociedade; a partir da 
reflexão e da sistematização de sua realidade - para garantir seus princípios, necessidades e objetivos. Para perceber suas fragilidades e suas potencialidades - para provavelmente, se constituir como parte de um planejamento coletivo e continuado.

O PPP, por isso, está sempre incompleto e inconcluso, porém, nem todos os sujeitos nele envolvidos têm essa noção. Daí possa se constituir num documento que pode revelar e reforçar a fragmentação, a departamentalização, a descontextualização e, obviamente, sua própria condição de existência. Se ao invés disso, queremos construir um documento que considere a realidade escolar, no sentido de promover uma continuidade de suas ações e intenções, o PPP possibilita ao conjunto dos envolvidos na escola, que pensem sobre si, que revejam seus instituídos e promovam seus instituintes. Gadotti (2012, p. 37) assim propõe: "um projeto político-pedagógico não nega o instituído da escola que é sua história, que é o conjunto dos seus currículos, dos seus métodos, o conjunto dos seus atores internos e externos e seu modo de vida. Um projeto sempre confronta esse instituído com o instituinte".

O PPP, portanto, trata de um convite feito à escola, no sentido de sua própria interpelação, de perguntar-se sobre si, e assim, ir além, superar-se, promover outros fazeres na busca de ultrapassarse. Isso, porque, necessita analisar, compreender e propor seus movimentos - a si mesma. Ter clareza acerca do tempo-espaço em que se insere e o que planeja construir.

Para Frigotto (2012, p. 09-10) a construção do projeto político-pedagógico, por isso,

pressupõe uma orgânica articulação com a sociedade imediata - bairro ou comunidade local, vila, cidade - e vínculos mediatos com a esfera estadual, nacional e global. O ponto de partida da produção material da vida e da produção social do conhecimento, da cultura e da cidadania é sempre local. Este conjunto de relações, todavia, não pode fixar-se no local, sob pena de se tornar antidemocrático.

Essa ação que dialoga com o local, sem perder de vista o global é uma das contribuições mais instigantes do processo que se instaura com a construção, implementação e reconstrução do projeto político-pedagógico. Contudo, não é tarefa fácil. Mas é preciso ter clareza do que se quer, daquilo que se deseja superar, para então, produzir um documento que se faça a favor de seu papel social, das suas necessidades e dos seus objetivos.

\section{DIÁLOGOS SOBRE O PPP: CONTRARIEDADES E OUTRAS VIABILIDADES}

Como vimos até aqui, as escolas que participam dessa pesquisa são três. Localizadas em bairros distantes uns dos outros, mas com populações bastante semelhantes do ponto de vista sócioeconômico-cultural, que terão aqui seus projetos em pauta. As dimensões da análise pretendem um diálogo entre os documentos, as entrevistas e a relação com a compreensão acerca da gestão, na perspectiva do trabalho coletivo entre a unidade escolar e a sede da secretaria municipal de educação, como órgãos do sistema municipal de educação. Esses temas, articulados, marcam posições e contraposições que a nós chamou atenção, a respeito dos movimentos, dos debates, dos fazeres e das ações educacionais. 
Partimos, por isso, explicando que todos os PPPs analisados foram construídos pela primeira vez, por determinação da secretaria municipal de educação, no ano de 2012. Nessa circunstância, após a leitura desses documentos foi planejada a entrevista semiestruturada, que ora contou com questões semelhantes e outras mais relacionadas a cada texto para servirem de diálogo com o grupo respectivo.

Uma das perguntas feitas, a todos os participantes, tinha por fundamento, investigar sobre o que os membros entrevistados, compreendiam pelo PPP, bem como o processo pelo qual foi realizado e se haviam participado dele. Grosso modo, encontramos um reconhecimento de que o PPP é bastante importante para a escola. Também relataram que sua feitura à época, contou com a participação da comunidade escolar (pais, alunos, professores e funcionários). E que a Secretaria Municipal de Educação realizou um conjunto de formações acerca do que seria, para que então, pudessem realizá-los. Porém, essas respostas remetem a uma contradição com o que já havíamos explicitado anteriormente sobre o que seria o PPP, bem como com a própria importância dada a ele, por todas as equipes entrevistadas. Ou seja, a contraposição reside entre relevância justificada ao documento e ao seu caráter de articulação entre o dia a dia da escola.

Disso, podemos problematizar: para que, então, serve esse projeto? Pois, como vínhamos afirmando, seria um instrumento que deflagraria aquilo que a escola necessita, para qual sociedade querem contribuir a formar. E na sequência, irromperia um processo de planejamento do qual lançariam mãos para isso acontecer. Sendo assim, parece-nos que estamos distante desse objetivo, pois antagonicamente, constatamos numa ou noutra realidade, que no PPP revela sim, uma clara reflexão do cotidiano, como por exemplo, registra um grupo distinto de questões, que apontam para preocupações com aquilo que poderia melhorar na escola, porém, não desencadeia um conjunto de ações para que tal superação aconteça, ou minimamente, que há já empenho detalhado para alcançála.

Assim, por exemplo, listam os seguintes problemas e considerações: o número de alunos por turma, considerando o tamanho das salas de aula; a evasão e o fracasso escolar; metodologias que possam reconhecer a construção do conhecimento e o aluno como protagonista de sua aprendizagem; o atendimento qualificado para a educação especial; as dificuldades quanto à sala de informática; um currículo que esteja em sintonia com a vida dos alunos - e tantos outros. Porém, não há um encaminhamento frente à operacionalização de tantas questões a serem reparadas e superadas. Os PPPs configuram-se mais como objeto que não contribuiu para a autonomia da escola, para a superação dos seus desafios, para aquilo que the é princípio, do que efetivamente um documento que serve para a escola se fazer, a partir do que deseja ser. Em síntese, nenhum efetivo trabalho planejado e continuado a partir dele.

Dito isso, estamos produzindo um entendimento de que os PPPs parecem ter sido gerados num momento em que se compreendeu necessário, talvez por um cumprimento legal, afinal, como já dissemos anteriormente, a Lei de Diretrizes e Bases (BRASIL, 1996) propõe em seu artigo 14, a elaboração dos projetos pedagógicos, de forma participativa, como princípio da gestão democrática. Porém, isso também não explicaria realizá-lo mais de uma década após ter sido redigido. O que pode significar é justamente a compreensão de uma visão administrativa gerencialista e tecnoburocrática do 
planejamento e da gestão educacional, pois desvinculado de um sequente plano de ações, ou de uma constante leitura e apropriação do que propunha como necessário a ser efetuado, modificado, não garantiu um de seus principais fins, chegar, continuamente, a mexer com a vida diária da escola. Ou melhor, não ajudou a compor um compromisso entre todos os membros da comunidade escolar a respeito de seus efetivos problemas que seriam solucionados no decorrer do planejamento.

O PPP, por isso, é, sem dúvidas, uma parte importante do planejamento da escola, mas não é seu ponto final. Cabe a gestão criar maneiras de implementá-lo, também, participativamente. Do contrário, possivelmente tenham resultado num produto estereotipado, desarticulado do contexto e possivelmente propenso ao esquecimento. Isso está demonstrado na desatualização dos documentos e no distanciamento deles com os Planos de Trabalho e com o fazer diário na escola. Eles existentes, mas não ajudam a operar mudanças necessárias nas escolas, às quais estão, inclusive, neles registradas.

De outro modo, é possível depreender que as mudanças acontecidas entre os membros das equipes diretivas e pedagógicas não propiciaram uma efetiva apropriação dos projetos políticospedagógicos e sua construção naquela instituição. Vimos isso, principalmente numa escola em que nenhum dos membros atuais da equipe gestora, participaram de sua elaboração, o que evidenciou que ao chegarem não tinham um compromisso com o que já havia sido construído. Isso pode significar a ideia de que o PPP possa ser um produto burocrático, que deve ser feito, porque a mantenedora (nesse caso a sede da secretaria municipal de educação), ou a lei exigem, descontextualizado de seu papel de servir à autonomia da instituição escolar e à sua gestão democrática - que não produz nenhuma melhoria na prática escolar, comunicando uma oposição, mesmo que de forma oculta, no sentido de que diante de tantas urgências e da dinamicidade que ocorre o cotidiano da escola, não contribui para ir além delas.

Na entrevista, por exemplo, essa mesma equipe chegou a pontuar que também a SMED não "cobrou", nem propôs ações para que ele fosse implementado, nem revisto. Assim, parece também que a escola se acomoda gentilmente à sua submissão hierárquica, subordinando-se única e exclusivamente ao seu órgão superior.

Com tudo isso, parece-nos possível considerar que os PPPs não estão fazendo-se como parte do processo de planejamento, nem evidenciando sua própria necessidade, no sentido de manifestar como seus problemas podem ser resolvidos. Obviamente, não estamos defendendo, nem tampouco simplificando o difícil e conturbado cenário que envolve os dilemas da escola. Contudo, é preciso reconhecê-los e a partir daí traçar um conjunto de ações para ir além. Nesse sentido, justificamos a importância da relação entre as escolas e sua mantenedora. Afinal, não há como propor políticas educacionais, nem no âmbito municipal, sem que os atores que vivenciam o cotidiano escolar possam dizer sua palavra, os obstáculos que experimentam todos os dias. E a sede da secretaria de educação também necessita ser parceira na execução daquilo que deve ser modificado na escola. Esta é uma relação dialética entre o estabelecimento escolar e o órgão que lhe mantém.

Vejamos a seguinte situação a respeito do que estamos propondo: após a confecção dos PPPs, houve uma mudança na administração municipal que culminou com uma nova equipe também na SMED. Ora, como já é de se esperar, a "nova" equipe partiu do marco "zero". Como se não 
houvesse vida na escola até então, ingressou e apontou o que deveria ser realizado - os "planos de estudo". Dessa forma, também a mudança das equipes escolares oportunizou sua "nova" administração, passando, assim, a fazê-los, sem recorrer ao seu projeto pedagógico

Assim, compreendemos que quando a SMED reforçou a importância dos Planos de Estudo em detrimento do PPP, estava favorecendo uma lógica da empresa capitalista, a qual tem em sua finalidade a produção de bens materiais para sustentação de sua lucratividade (PARO, 2015). Sobre isso, a escola pública em questão, não tem nenhuma similaridade. A educação ao contrário disso, tem uma modalidade de produção não-material, em que produto e produção são inseparáveis (FÉLIX, 1986; PARO, 2011) e talvez por isso mesmo, necessite tanta força administrativa, tanto regramento, tanta normatização e tamanha descontinuidade, pois, somente assim, é possível que se demarque sua consolidação como parte da lógica do capitalismo. Essa separação entre produto e produção, sujeito e objeto, meio e fim é o que caracteriza a racionalidade instrumental, técnica (CARVALHO, 2009) e que define o modelo empresarial na sociedade capitalista.

A partir dessa compreensão, questionamo-nos por que os gestores da escola passaram a cumpri-lo, reforçando seu aspecto de submissão e abdicando de sua autonomia. É possível propor um entendimento de que "abriram mão" do trabalho desenvolvido até então, porque talvez, tenham sido fruto de uma obrigação provavelmente normativa, do órgão hierarquicamente superior, não significando como já vimos, a intenção da escola em se por, efetivamente, a elaborar seus processos para a construção dos seus ideais. Nesse sentido, a equipe gestora da unidade escolar, assegura uma gestão descomprometida com o trabalho realizado quando da construção do PPP, pois se houvesse clareza sobre a importância de tal realização, poderiam buscar nela os elementos para a consolidação de um plano de trabalho, mesmo que distanciando-se das prescrições de sua mantenedora.

Sendo assim, o pensamento de Lima (2000) nos é bastante promissor, pois de um lado temos o que chama de "despolitização da organização escolar" (p. 17) - entendida como uma subordinação a ideologias generalistas e neocientíficas, em que sua autonomia é meramente instrumental; e de outro modo, desenvolve um entendimento de que, a autonomia além de ser processo, está capturada por implacáveis contradições entre os princípios democráticos, que fundamentam a participação, a dialogicidade, a partilha do poder; e uma organização escolar que necessitaria estar articulada com seu sistema e não submissa a ele.

Para Neves (2013) a autonomia exige relação sistêmica, reconhecimento da liberdade, - em interrelação. Portanto, para a autora, a autonomia não é outorgada, mas é possibilidade. Para isso, os sujeitos da escola precisam sentir que são capazes de desenvolvê-la, e isso requer que se sintam responsáveis por sua instituição, seu devir, caso contrário, será sempre uma "boa desculpa" argumentar que foram tolhidos e coagidos a fazerem o que desejava o órgão central do sistema educacional.

Sendo assim, perguntamo-nos também a quem caberia articular todas essas ações? Possivelmente seria bastante compreensível respondermos que seria à SMED e as equipes gestoras das escolas municipais. Essa seria uma boa articulação. E foi efetivamente para esse fim que empreenderam uma ação de construírem uma "Carta de Princípios" da/para a Rede Municipal de Educação. O sentido atribuído a esse fazer foi o de realizar uma produção coletiva, como "polo 
aglutinador de intenções, de interações e de forças que caminham juntas" (MOTTA et al, 2012), para que se tornassem reveladoras dos propósitos da rede e orientadora na reconstrução daqueles. A partir das discussões entre equipes, PPPs existentes e profissionais das escolas, numa dimensão de diálogo entre os envolvidos do contexto educacional, chegaram a formulação de sete campos de atuação e suas compreensões - e passariam a dar suporte à reconstrução dos projetos políticos-pedagógicos: a) gestão democrática, b) clima escolar, c) convivência, d) processo ensino-aprendizagem, d) currículo, e) avaliação, f) metodologias.

\section{PROVOCAÇÕES SOBRE A GESTÃO - DECISÕES POLÍTICO-PEDAGÓGICAS}

Frente ao que estamos compartilhando, mantenedora e escolas municipais iniciaram um trabalho que possibilitasse um processo para a reconstrução dos PPPs das unidades escolares, em que os gestores delas, compondo aqui, as funções da administração escolar, ou seja, os supervisores, orientadores, diretores e vice-diretores - voltaram-se para suas instituições e, de posse dos PPPs existentes, resgataram o que propunha e do que não dispensariam para a consolidação de uma rede educacional perspectivada à uma educação humanista, cidadã - que desejavam ser. Esse foi o objetivo que pautou a elaboração da "Carta de Princípios".

A singularidade de cada projeto de escola é vital para a compreensão de sua importância e isso acarreta reconhecer sua própria autonomia e sua diversidade, mas ao mesmo tempo há a composição da rede de ensino, em que as políticas educacionais se inserem no sentido de uma possibilidade de organização coletiva e articulada. Foi isso que a realização da "Carta" significou, para além de uma mera prescrição acerca da elaboração dos PPPs, as próprias escolas elaboraram os pressupostos do que serviria para a reconstrução dos documentos. Isso contrapôs a condição de homogeneidade, que geralmente desencadeia um processo de compreensões que documento corresponde a um ato meramente formal a partir de procedimentos padronizados e, nessa contraposição, torna-se único de cada escola, mas ao mesmo tempo com os mesmos propósitos, os quais constituem a rede de ensino, materializando, portanto às finalidades do próprio sistema de ensino em que está inserido. Como Fonseca (2003) propõe no trabalho acerca do PDE (Plano de Desenvolvimento da Escola) e do PPP, onde o primeiro está para uma abordagem do gerenciamento e o segundo para autonomia e identidade da escola. "Além disso, busca superar a gestão dos meios e produtos, apelando para iniciativas inovadoras, orientadas por valores mais humanos e que levem em conta vivências e sentimentos, condições de vida e de trabalho, à cultura e qualificação dos professores." (FONSECA, 2003, p. 306).

E no que refere à relação escola e mantenedora, Veiga (2013, p. 15) propõe que

\footnotetext{
Se a escola nutre-se da vivência cotidiana de cada um de seus membros, coparticipantes de sua organização do trabalho pedagógico à administração central, seja o Ministério da Educação, a Secretaria de Educação Estadual ou Municipal, não compete a eles definir um modelo pronto e acabado, mas sim estimular inovações e coordenar as ações pedagógicas planejadas e organizadas pela escola.
}

A construção de que falamos aqui, reconhece como imprescindível os fazeres que envolvem reflexão e ação, ambas originadas na perspectiva de compromisso com a educação/escola. Nessa 
perspectiva, defendemos uma gestão dos espaços educativos, ancorada na pedagogia, sendo capaz de tecer a inter-relação entre todos os atores, setores e devires que constituem a educação. Essa gestão terá como uma das suas principais funções desenvolver de forma efetiva e coletiva, uma ampla organização articulada às necessidades da escola e que culminará num planejamento políticopedagógico. Desse mesmo modo, Lima (2000) tratá-la-á como governação, porque significa processo diante da "ação de governar", para além das prescrições meramente normativas. É, assim, tomada "a partir de contextos organizacionais e de estruturas de poder de decisão, mas que também interferem na construção e recriação dessas estruturas, por meio de formas mais democráticas de exercer os poderes educativos no sistema escolar, na escola, na sala de aula etc." (LIMA, 2000, p. 19).

A gestão, portanto, que acontece na relação entre a SMED e as escolas advém de uma escolha que busca valorizar mais o coletivo, entre os diversos profissionais que a compõem. De forma a garantir os saberes, os fazeres e os desafios que ali circulam. Porém, há que se destacar que isso é uma ruptura com os padrões mais valorizados e ainda vivenciados nas estruturas administrativas dos sistemas educacionais, que ao fim e ao cabo, foram amplamente orientados para métodos administrativos típicos da empresa privada (ARROYO, 1979).

Por isso há que se compreender que

\begin{abstract}
A administração escolar é mediadora dos interesses que se manifestam em relação à educação no âmbito da sociedade e da escola. Dessa forma, ela poderá estar a serviço tanto da conservação quanto da transformação da ordem social, entendida esta, no seu sentido radical, como a superação da sociedade de classes. (RUSSO, 2011, p. 510).
\end{abstract}

Nesse sentido, há um componente ideológico na escolha do tipo de administração que se irá adotar. O que significa que os rompimentos com modelos mais burocratizados, tecnicistas e que reforçam o ideal protagonizado pelo mercado, não é tarefa fácil, mas possível, e que necessita uma prática reflexiva permanente sobre a gestão.

Frente a isso torna-se premissa, num primeiro momento, realizar uma ampla construção com todos aqueles que ainda sonham com uma escola mais bonita - e isso foi um dos movimentos instituídos na reconstrução do PPP. Como uma instituição escolar democrática - necessita ser proativa em relação aos desinteresses e acomodações (CARVALHO, 2009). Isso não exclui, obviamente, os demais, aqueles que por uma razão ou outra não sonham mais. Desistiram. Ou estão apenas adormecidos. Mas, ao contrário, inclui no processo decisório e corresponsável aqueles que efetivamente querem reinventar a própria escola.

\title{
CONSIDERAÇÕES FINAIS
}

O PPP foi-nos elemento de análise que possibilitou discutir algumas interfaces entre a Sede da Secretaria Municipal de Educação e as escolas por ela mantidas, desde a elaboração do documento e, posterior desencadeamento. Ou seja, o PPP pode ser considerado importante, mas pode acabar absorvido pela rotina do fazer escolar e ser inclusive, secundarizado no processo, ou deixado de lado, ou pode ser usado para dar cabo do universo burocratizante, em que os membros da equipe valem-se 
para fazer cumprir as normas que regem a escola. Ou ainda, reconstruído e utilizado cotidianamente, dando sequência a um processo de constante alcance dos seus objetivos e de sua autonomia, que propõe a consolidação de forças para o desafio de construir uma escola democrática, popular e socialmente justa.

Então, reforçamos que a pesquisa que escolhemos vivenciar, sustenta-se da concepção de que é possível mudar uma determinada situação, levando em conta a amplitude de seu contexto (DIONNE, 2007). Nesse sentido, torna-se imprescindível a reflexão sobre o projeto de escola e sua relação com a totalidade, e diante disso, fortalecer sujeitos e processos coletivos e participativos de sua construção e

implementação. É, pois, sobre essa proposição que a investigação objetivou - buscar as articulações entre SMED e escola para a garantia de um projeto e seu desenrolar, seu desenvolvimento e daí decorrendo um conjunto de políticas. Porque a escola precisa se pôr a efetivar seu planejamento, como possibilidade de se refazer. Ao contrário, pode calcar-se sobre os velhos grilhões que impulsionam as dicotomias entre administrativo $\mathrm{X}$ pedagógico, pensar $\mathrm{X}$ fazer, mandar $\mathrm{X}$ obedecer.

Por isso, não bastam leis e normatizações para que a escola se coloque a desenvolver uma gestão democrática, que pode ser analisada pela elaboração e execução do seu PPP, por exemplo. Outrossim, a ideia de disputa traz a possibilidade de não haver uma ênfase tão consolidada acerca das certezas da gestão. O PPP, portanto, forjado na participação e direcionado para a validação de um projeto de escola, de sua autonomia, auxilia-a, mas é preciso que seja para além de sua elaboração escrita. É necessário que haja um efetivo envolvimento como produção da política municipal, por isso ações que reflitam na consolidação da rede educacional, da mantenedora em sintonia com a escola.

Isso tudo, soma-se o reconhecimento da importância que têm os PPPs das escolas. Nesse sentido de ser um documento parte do planejamento para a promoção de políticas educacionais que qualifiquem a escola há ainda muito a caminhar, porque será preciso que os órgãos públicos e a própria comunidade escolar possam se apropriar da tarefa de assumir sua função. Quanto colabora nas decisões, no fazer diário, em novas práticas de gestão das escolas, ou de outra forma, sua construção como "resposta", desencadeador de um planejamento que problematize os desafios vivenciados recorrentemente. Isso traz como aporte aos nossos estudos, a necessidade de evidenciarmos, o quanto dirigentes educacionais, por meio de uma gestão democrática e participativa, têm a contribuir para a autonomia da escola.

\section{REFERÊNCIAS}

1. ARROYO, Miguel Gonzales. Administração da educação, poder e participação. Revista Educação \& Sociedade - CEDES, jan. 1979. p. 36-46.

2. BRASIL. Lei n. 9394, de 20 de dezembro de 1996. Lei de Diretrizes e Bases da Educação Nacional. Brasília, 1996. 
3. CARVALHO, Maria Joao de. Paulo Freire: a construção da escola democrática a partir da decisão. Revista Brasileira de Política e Administração da Educação. v.25, n. 3, set./dez. 2009, p. 441-454.

4. COSTA, Daianny Madalena. PROJETO POLÍTICO-PEDAGÓGICO: uma possibilidade de gestão democrática. Revista Exitus, Santarém/PA, Vol. 7, № 1, p. 200-221, Jan/Abr 2017. p. 200-221.

5. DIONNE, Hugues. A pesquisa-ação para o desenvolvimento local. Brasília: LiberLivro Editora, 2007.

6. ESTÊVÃO, Carlos A. Vilar. Gestão escolar e formação. IN: MACHADO, Lurdes Marcelino; FERREIRA, Naura Syria Carapeto (orgs). Políticas e Gestão da Educação: dois olhares. Rio de Janeiro: DP\&A Editora. 2002. p. 83-106.

7. FÉLIX, Maria de Fátima Costa. Administração escolar - um problema educativo ou empresarial? $3^{a}$ ed. São Paulo: Cortez Editora: Autores Associados. 1986.

8. FONSECA, Marília. O Projeto Político-Pedagógico e o Plano de Desenvolvimento a Escola: duas concepções antagônicas de gestão escolar. Cad. Cedes, Campinas, v. 23, n. 61, p. 302-318, dezembro 2003. Disponível em http://www.cedes.unicamp.br. Acesso em: 28 de fev. de 2018.

9. FRIGOTTO, Gaudêncio. Apresentação. In: GADOTTI, Moacir; ROMÃO, J. Eustáquio (orgs). Autonomia da escola: princípios e propostas. $7^{a}$ ed. São Paulo: Cortez. 2012.

10. GANDIN, Danilo: GANDIN, Luís Armando. Temas para um projeto político-pedagógico. $12^{\mathrm{a}}$ ed. Petrópolis/RJ: Vozes, 2011.

11. GADOTTI, Moacir. Projeto Político Pedagógico: fundamentos para sua realização. IN. GADOTTI, Moacir; ROMÃO, Eustáquio. Autonomia da escola: princípios e propostas (org.). $7^{a}$ ed. São Paulo: Cortez, 2012. p. 36-46.

12. GHEDIN, Evandro. FRANCO, Maria Amélia Santoro. Questões de método na construção da pesquisa em educação. São Paulo: Cortez, 2008. (Coleção docência em formação. Série saberes pedagógicos).

13. LIBÂNEO, José Carlos; OLIVEIRA, João Ferreira de; TOSCHI, Mirza Seabra. Educação escolar: políticas, estrutura e organização. $10^{\mathrm{a}}$ ed. Rev. e ampl. São Paulo: Cortez, 2012. (Coleção docência em formação: saberes pedagógicos).

14. LIMA, Licínio C. Organização escolar e democracia radical: Paulo Freire e a governação democrática da escola pública. São Paulo: Cortez: Instituto Paulo Freire, 2000. (Coleção Guia da Escola Cidadã, v. 4).

15. MORAES, Roque. Uma tempestade de luz: a compreensão possibilitada pela análise textual discursiva. Ciência \& Educação, v. 9, n. 2, 2003. p. 191-211. 
16. MOTTA, Custodio Gouvea L. da et al. Carta escolar: instrumento de planejamento coletivo. IN: GADOTTI, Moacir; ROMÃO, José E. Autonomia da escola: princípios e propostas. $7^{a}$ ed. São Paulo: Cortez, 2012. p. $57-73$.

17. MINAYO, Maria Cecília de Souza. O desafio da pesquisa social. IN: MYNAIO, Maria Cecília de Souza; DESLANDES, Suely Ferreira: GOMES, Romeu. Pesquisa social: teoria, método e criatividade. Petrópolis: Vozes, 2016.

18. NEVES, Carmem Moreira de Cartro. Autonomia da escola pública: um enfoque operacional. In: VEIGA, IIma Passos Alencratro (org.). Projeto político-pedagógico da escola: Uma construção possível. 29a ed. Campinas, SP: Papirus, 2013. p. 95-129. (Coleção Magistério: formação e trabalho pedagógico).

19. PARO, Vitor Henrique. Crítica da estrutura da escola. São Paulo: Cortez, 2011.

PARO, Vitor Henrique. Diretor escolar: educador ou gerente? São Paulo: Cortez, 2015.

21. ROLDÃO, Maria do Céu. A mudança anunciada da escola ou um paradigma de escola em ruptura? IN: ALARCÃO, Isabel. Escola reflexiva e nova racionalidade. Porto Alegre: Artmed. 2a ed. 2003.

22. RUSSO, Miguel Henrique. Escola e paradigmas de gestão. São Paulo, EccoS Revista Científica, vol. 6, núm. 1, junho, 2004, p. 25-42.

23. RUSSO, Miguel Henrique. Trabalho e administração da escola: desenvolvimento e apropriação do sentido que assumem no processo de produção pedagógica. RBPAE - v.27, n.3, p. 361-588, set./dez. 2011.

24. STRECK, Danilo R.; ADAMS, Telmo. Pesquisa participativa, emancipação e (des)colonidade. $1^{\text {a }}$ ed. Curitiba/PR: CRV, 2014.

25. VEIGA, IIma Passos Alencastro. Projeto político-pedagógico da escola: uma construção coletiva. IN: VEIGA, IIma Passos Alencastro (org). Projeto político-pedagógico: Uma construção possível. Campinas/SP: Papirus. 29a ed. 2013. p. 11-35. (Coleção Magistério: Formação e Trabalho Pedagógico).

\section{Daianny Madalena Costa}

Professora permanente do Mestrado Profissional em Gestão Educacional - MPGE.

\section{Como citar este documento:}


COSTA, Daianny Madalena. O PROJETO POLÍTICO-PEDAGÓGICO - CONSIDERAÇÕES ACERCA DA GESTÃO PARA A AUTONOMIA DA ESCOLA. Reflexão e Ação, Santa Cruz do Sul, v. 29, n. 1, p. 215-228, jan. 2021. ISSN 1982-9949. Acesso em:_doi: http://dx.doi.org/10.17058/rea.v29i1.12513 